\title{
SSinteza
}

Impact of Internet on Business Activities in Serbia and Worldwide

Uticaj Interneta na poslovanje u Srbiji i svetu

DOI: 10.15308/SINTEZA-2014-450-453

\section{ETIKA: TEMELJ ŽIVOTA I RADA}

\author{
Miroljub Albijanić \\ Singidunum Univerzitet
}

\begin{abstract}
:
Osnova etike je ispravno postupanje ljudi, od ranih civilizacija do danas. Rad otkriva koje postupanje smatramo dobrim i ispravnim i kako etika utiče na osnovna životna pravila. Sa druge strane etika nam pomaže da bolje i efikasnije radimo.
\end{abstract}

Key words:

etika, vrlina, prirodni zakon, utilitarizam.

\section{UVOD}

Osnova etike je ispravnost koja se tiče svakog čoveka, i koja je izgrađena nezavisno od pretpostavki koje važe u životu ili u religiji, ili nezavisno od autoriteta običaja, predaka ili pozitivnog zakona. Ljudi tragaju za smislom datih različitih pravila i nastoje da ga odmere međusobno sa vrhovnim sudijom - sa smislom morala kao celine. Glavni deo rada čine Elementi helenske etike. Uzor za ovu oblast je profesor Miloš Đurić. Prema njemu helenska etika je filozofsko učenje o moralnom ponašanju i to je etika čistog saznanja, etika zadovoljstva, etika volje, etika vrline ili etika dužnosti.

\section{ETIKA NA ISTOKU}

\section{Egipatska etika}

U srcu egipatske etike nalazio se ma'at pojam koji označava pravednost, ravnotežu, normu, poredak, istinu, ono što je korektno i ispravno postupanje. Solomonove priče izdvajaju dve vrste ljudi: mudre - koji slušaju božji zakon i koji su dobri građani, odmereni, razboriti, pouzdani, pošteni, koji pravedno govore, poslušni, marljivi, koji pravedno sude i zle koji ne poštuju zakon. Postoje i dve vrste žena: dobre koje su idealne supruge, čija glavna briga jeste dobrobit porodice i muža, koje marljivo rade $\mathrm{i}$ upravljaju kućom i zle koje su razvratne pustolovke. Ove osobine vode ka uspehu ili neuspehu i nevolji.

Najviše dobro u Indiji se poistovećuje sa totalnom harmonijom kosmičkog i prirodnog poretka. Ljudsko ponašanje, kroz društveni i moralni poredak ali i stvaralaštvo, je korelat prirodnog poretka, uređeni tok stvari, istina bića ili stvarnosti i zbog toga Zakon. Na strani dobra su sreća, zdravlje, opstanak, potomstvo, zadovoljstvo, mir, prijateljstvo, znanje i istina.
Bramansko društvo izdvaja ljudske vrline i moralne ideale kao što su istinoljubivost, davanje, uzdržavanje, zahvalnost, praštanje, davanje drugima ono što su pravedno zaslužili i izbegavanje povređivanja svakog bića.

\section{Hindu etika}

Klasična hindu etika čine četiri važna činioca: [1, s. 71]

- Ashrama (životni ciklus) sastoji se iz četiri faze kocentrična kruga: (1) doba učenja koje zahteva disciplinu i čednost; (2) domaćinsko doba koje sa sobom povlači brak, porodicu i obaveze prema njima; (3) doba delimičnog povlačenja koje traži postepeno napuštanje obaveza i zadovoljstava; i (4) odricanje koje vodi ka potpunom povlačenju i kontemplaciji.

- Dharma (dužnost) je sveobuhvatan sistem principa, ophođenja, dužnosti, ispravnosti, pravičnosti, morala, vrline, religije, dobrih dela i istine.

- Karma (delo i posledica) na skriven način nešto kao duša nosi sve što konstituiše ličnost. Po zakonu karme nagrađuju se zasluge i vrline a kažnjavaju zla dela.

- Purusharthas (ljudski ciljevi) su četiri težnje koje imaju suštinsku vrednost: artha, materijalni interesi; kama, uživanje i emotivno ispunjenje, dharma, društvene i individualne dužnosti; i moksha, oslobođenje.

U Budizmu etika ima društvenu dimenziju ali i lično traganje za ispravnim životom, koji odlikuju upražnjavanje vrlina i meditiranje. Plemenite istine su: (i) istina o patnji, (ii) istina o nastanku patnje, (iii) istina o prestanku patnje i (iv) plemeniti osmostruki put o nestanku patnje [(1) ispravno shvatanje, (2) ispravna namera, (3) ispravan govor, (4) ispravna telesna aktivnost, (5) ispravan način 
života, (6) ispravan napor, (7) ispravna pažnja, (8) ispravna sabranost].

U budizmu se izdvaja šesnaest zagađenja duha: pohlepa, pohota, zloba, bes, pakost, licemerje, prkos, zavist, škrtost, obmana, izdaja, tvrdoglavost, plahovitost, osionost i uobraženost. Desetostruko zlo postupanje je ubistvo, krađa, izopačeno uživanje, laž, kleveta, lakomislenost, požuda, zloba i pogrešna uverenja.

Buda je od ljudi zahtevao, ne samo da izbegavaju zla već i, da upražnjavaju pozitivne moralne vrline. Prema Valasovoj (Wallace, 1978, Virtues and vices) analizi to su (1, s.97):

- vrline savesnosti: istinoljubivost, vernost i pravednost;

- vrline čovekoljublja: dobrota srca, samilost, saosećajna radost i duševni mir;

- vrline samoodricanja: samosavladavanje, zdržanost, strpljenje, neporočnost, čistota.

Ljudi su, kroz pošten i umešan napor, posvećeni sticanju bogatstva, a kroz štedljivost i umeren život njegovom očuvanju.

Po kineskom pristupu nama upravlja društveni tao (put). Prevod reči etika na kineski je tao te što znači putevi i vrline. Konfučije je bio najpoznatiji mislilac klasičnog perioda. On je prenosio $l i$ što označava obred, propisano ponašanje, manire, ceremonije $\mathrm{i}$ ispravnost.

„Konfučije je stvarno formulisao negativnu verziju Zlatnog pravila. Ono što ne želiš sebi, ne čini drugima. Ovo se može shvatiti i kao tumačenje uzajamnosti." (1, s.108) $\mathrm{Mo} \mathrm{Cu}$ je nasledio veći deo društveni tao od Konfučija ali je razvio i sistem shi (ispravno, treba) i fei (neispravno, pogrešno). Po njemu ovo merilo ima osnov u prirodnoj ili nebeskoj volji. U prirodi je to sklonost ka korisnom umesto ka štetnom. Korisnost ovde nije subjektivna (uživanje, sreća) već je objektivna, materijalna dobrobit.

Mencije utvrđuje četiri jezgra iz kojih se razvijaju primarne vrline. Prvo je ljudsko saosećanje, i zbog njega radimo u korist drugih ljudi. Kad se potpuno razvije postaje vrlina čovečnosti. Drugo jezgro je naša sklonost da osećamo stid i iz nje se razvija moralnost (moral je organski). Treće se odnosi na spremnost da ukazujemo poštovanje i poslušnost onima koji su nam društveno nadređeni. I četvrto, u nama postoji urođena tendencija da razlikujemo shi-fei. Ova sklonost usmerava naše postupanje i prerasta u praktičnu mudrost $z h i$ (saznanje).

Šablon se koristi kako bi formatirali i stilizovali tekst. Propisane su sve margine, širine kolona, prored i tekstualni fontovi; nemojte ih menjati. Primetićete specifičnosti. $\mathrm{Na}$ primer, „head margin“ je u ovom šablonu proporcionalno

\section{ELEMENTI HELENSKE ETIKE}

\section{Demokrit}

Demokrit ističe, najviše dobro je blaženstvo koje se sastoji iz trajne duhovne vedrine, odnosno harmonije i ravnoteže. Uslov za postizanje blaženstva je (1) održavanje mere, jer „lepa je u svemu prava mera, prekomernost i nedostatak ne mile mi se“; (2) ispunjavanje dužnosti,
"Pravičnost se sastoji u ispunjavanju svoje dužnosti, a nepravičnost u njenom zanemarivanju. Ispunjavanje dužnosti izvor je duhovne vedrine, snage i spokojstva, a zanemarivanje stvara nezadovoljstvo, nemir i mučenje samog sebe." (3) rad i napor, jer ko traži dobro nalazi ga samo radom, a plemenite stvari stiču se napornim učenjem. [2, s.167]

\section{Sokrat}

Sokratov etički ideal glasi: vrlina je znanje. Vrlina je dostižna jer može se naučiti. „Razmisli dovoljno duboko, govorio je on, i uvek ćeš pronaći da je ispravno postupanje najbolje za tebe." Ksenofont piše da Sokrat, mudrost (u teorijskom smislu) i moralnost (u praktičnom smislu) nije razlikovao, nego je za onoga ko zna šta je lepo i dobro pa to i primenjuje, kao i za onoga ko zna šta je ružno pa se toga i kloni, smatrao da je mudar i moralan. Sve što služi određenoj svrsi jeste dobro, a ono što je dobro to je lepo, korisno i prijatno. Korist je samo sredstvo za dostizanje blaženstva - najvišeg dobra, koje predstvlja trajno zadovoljstvo što ga stvara dobar rad i lep napredak. Prava vrlina je znanje koje čoveka čini blaženim. (Napomena, ono što je dobro to je i prijatno, ali ne mora da važi da ono što je prijatno bude i dobro).

\section{Platon}

Platon je osnovao akademiju sa ciljem zajedničkog učešća u slobodnom obrazovanju novog naraštaja - aristokratije duha i karaktera. Apsolutnu i pravu stvarnost predstavljaju ideje kao predmeti pojmovnog i, pravog saznanja, a predmeti čulnog saznanja predstavljaju relativnu stvarnost, tj. svet stvari koje postaju i nestaju. $\mathrm{Na}$ krajnjoj granici našeg saznanja „vidi se“ ideja dobra, ona je uzrok svake pravde i lepote; u vidljivom svetu rađa svetlost; a u svetu u kome je ona gospodar daje nam istinu i um. „Svojim pravim bićem duša pripada natčulnom svetu, a kako samo u njemu ima pravog i trajnog bića, može se blaženstvo, koje je poslednji cilj ljudskog života, postići samo tako ako se čovek trudi da se uzdigne u onaj viši svet." $[2$, s.340]

\section{Prvo blaženo bitije $i$ istočnik besmrtne sreće, rajska polja, večito blaženstvo životvorni pogled stvoritelja \\ (Njegoš, Luča mikrokozma)}

Platon ističe da se prava vrednost života ne sastoji ni u zadovoljstvu ni u umnoj delatnosti, nego u takvom odnosu da umna delatnost ima vlast nad zadovoljstvom. A najvišu vrednost i draž daje spoj mere, lepote i istine.

Platon razlikuje četiri stožerne vrline: (i) mudrost (vrlina umnog dela, um unapređuje dušu i upravlja njenim životom); (ii) hrabrost (vrlina voljnog dela, jaka volja pokorava se umu o onome čega se treba ili ne treba bojati); (iii) umerenost (vrlina požudnog dela, volja i požuda pokoravaju se umu); (iv) pravednost (opšta vrlina). [2, s.346] 


\section{Aristotel}

Aristotel je smatrao da je krajnji (najviši) cilj onaj za koji se opredeljujemo uvek zbog njega samog, a nikada radi drugoga. „A takav je cilj, čini se, pre svega blaženstvo, jer njega svagda biramo samo radi njega, a nikada radi nečega drugoga, dok čast i uživanje i um i svaku vrlinu biramo, doduše i radi njih samih (jer ako i ne bismo ništa više postigli, opet bismo voleli svaku od tih stvari), a biramo ih radi blaženstva, smatrajući da ćemo baš njihovim posredstvom imati blaženstvo. Najviše dobro je blaženstvo, a blaženstvo se sastoji u delatnosti duše prema vrlini.

Aristotel pojam ljudske vrline svrstava u dve klase: klasu intelektualnih (logičkih) i klasu moralnih (etičkih) vrlina. „U intelektualne vrline spadaju: znanje, moć shvatanja odnosno inteligencija i pamet (odnosno praktična mudrost); a u moralne: plemenita velikodušnost i razboritost (odnosno vladanje sobom)." (3, s.24) Intelektualna vrlina stiče se i razvija podučavanjem, učenjem i revnosnim vežbanjem, i zato ona zahteva vreme i iskustvo, a moralna vrlina dolazi sa navikom i njen izvor jesete volja, a bitna osobina volje je sloboda. Sloboda volje je uslov moralnog delovanja. Vrlina ima posla sa strastima i postupcima, gde preteranost znači grešku, nedovoljnost donosi prigovore, a sredina (prava mera) dobija pohvale i uspeva.

Vrlina je prema tome izborna naklonost volje, koja se drži sredine podesne za sopstvenu prirodu, a određene razmišljanjem, i to onako kako bi se odredio razuman čovek. [2, s.390]

Dok Platon čovekov moral vezuje za natčulni svet ideja i težnju za sličnošću sa Bogom, Aristotel smatra da nije reč o dobru po sebi nego o ljudskom dobru, o onome što je dobro u ljudskom životu u kojem čovek nalazi razloge za svoje mišljenje i delanje.

\section{PRIRODNI ZAKON}

Ideja prirodnog zakona opisuje se kao shvatanje da postoji nepromenljivi moralni poredak, koji je deo prirodnog sveta. Za Aristotela najpotpunija ljudska osobina je racionalnost. Ako treba da odredimo šta je ljudska priroda, mi tragamo za unutrašnjim principom, koji na poseban način upravlja ljudskim žiivotom; a to je razum. Stoici su ljudsku prirodu shvatili kao deo prirodnog poretka i sačuvali su Aristotelovo naglašavanje razuma kod ljudskih bića, jer ljudski razum je iskra stvaralačke vatre, logosa koji je uredio i ujedinio svet. Prirodni zakon, zakon prirode jeste zakon ljudske prirode i taj zakon je razum, preciznije: prirodni zakon jeste zakon ispravnog ili zdravog razuma.

Klasična formulacija prirodnog zakona data je u slavnom objašnjenju Cicerona u delu De republica. „Pravi zakon je ispravan razum u saglasnosti sa prirodom; on je univerzalno primenljiv i neprolazan; on svojim zapovestima poziva na dužnost i svojim zabranama odvraća od rđavih dela." [1, s.239] Zakoni koji upravljaju ljudskim postupcima su u utemeljeni u prirodi kao pravila zajednička za sve. Na primer, Ciceron navodi, uspravan stav (koji je neophodan za široko i dalekovido shvatanje stvari), govor i sposobnost izražavanja (sposobnost za komunikaciju), prirodno saosećanje sa bližnjim (kao potpora društvenom životu i naravno, racionalno mišljenje. „Za gomilu zakon je ono što, u pisanoj formi, određuje sve što hoće bilo naredbom, bilo zabranom, ali za obrazovanog čoveka zakon je shvatanje čija je prirodna funkcija da zapoveda ispravno ponašanje i zabranjuje rđava dela - on je svest i razum pametnog čoveka, standard kojim se mere pravda i nepravda“ (Cicero, Zakoni) [1, s.240].

Toma Akvinski (1225-1274), u svom delu Summa Theologiae, zastupa racionalističko shvatanje moralnog mišljenja i smatra da se prirodni zakon može otkriti upotrebom ispravnog razuma. „Sve što je suprotno poretku razuma, suprotno je prirodi ljudskih bića kao takvih; a ono što je razumno, jeste u skladu sa ljudskom prirodom kao takvom. Dobro za ljudsko biće jeste život u skladu sa razumom." [1, s.241] Zakon je zapovest razuma za opšte dobro, to je pravilo i mera delovanja, na osnovu koga se čovek navodi na delovanje ili se odvraća od njega. Kao ekvivalent praktičnog ili ispravnog uma (recta ratio) navodi savest što je urođena sposobnost kojom se otkriva božiji moralni zakon, onako kako je zaspisan u ljudskim dušama. Prema Akvinskom, ispravno je ono postupanje koje ili teži ka unapređenju ili stvarno realizuje ljudsku sreću. Postoji osobena i suštinska ljudska priroda, a u vezi sa njom i skup vrednosti koje konstituišu izvrsnost ponašanja. Govoriti o prirodnom zakonu znači ukazati na onaj deo opšteg poretka stvari, koji uključuje ljudsku vrstu i njeno savršenstvo. [1, s.208]

Avgustin takođe ističe savest kojom čovek saznaje moralni zakon. Ovo saznanje nije dovoljno za vrlinu, već zahteva da i volja bude usmerena ka dobru. „Čovek posmatra moralna pravila, zapisana u knjizi svetlosti, koja se zove istina, koja su uzor svim drugim zakonima." [1, s.202]

Otac modernog prirodnog zakona je Grocijus, koji poriče suprotnost između ljudske prirode i korisnosti. Prirodni zakon nije utemeljen na koristi ali ga korist ojačava. Ovde treba napomenuti da nisu svi oblici utilitarizma (korisnosti) spojivi sa prirodnim zakonom.

Teorija prirodnog zakona može da se izrazi kao teorija (ograničenog broja) istinskih ljudskih dobara. Prema Finisu skup osnovnih dobara je, na primer, život, saznanje, igra, estetsko iskustvo, društvenost (prijateljstvo), praktični razum i religija.

Kant je zastupao ekstremnu formu shvatanja prema kome je moral izraz ljudske prirode. Centralno pitanje je šta treba da činim? Glavni smisao morala je u tome da postupamo po dužnosti, pokazujući nam šta da činimo u svakom pojedinačnom slučaju. Na početku je utvrđivanje dobre volje kao jedinog bezuslovnog dobra. Smisao je da ništa ne bi moglo da bude moralni princip, ako ne može da bude princip za sve ljude. Moral počinje sa odbacivanjem principa koji se ne mogu učiniti univerzalnim. Ova ideja je Kantov osnovni zakon čistog praktičkog uma: delaj takoda maksima tvoje volje uvek može istovremeno važiti kao princip sveopšteg zakonodavstva. [5, s.53] Kant zaključuje da je čisti um sam za sebe praktički i daje čoveku sveopšti zakon koji nazivamo moralnim zakonom. Najveće kulturno dejstvo imao je iskaz da ljudskost u sopstvenoj ličnosti ili u ličnosti bilo kog drugog nikada ne uzimamo kao sred- 
stvo, već uvek kao cilj. To je visok zahtev za poštovanje ličnosti. Svaka ličnost vredi podjednako, svakoj ličnosti pripada jednak značaj. „Ključ za Kantovo shvatanje je sloboda. Kad znamo da smo moralno obavezni da nešto učinimo, znamo da to i možemo da uradimo; a ovo može biti samo ako smo slobodni. Sloboda delovanja isključuje determinaciju bilo čim spoljašnjim, a takvo postupanje nije ni neodređeno ni slučajno." [1, s.221] Političke implikacije kategoričkog imperativa su poštovanje slobode, posebno slobode veroispovesti i govora. Koreni shvatanja univerzalnih ljudskih prava leže u učenju o prirodnom zakonu.

Ako je čovek prisiljen da bira između dobra koje je dobro za nekog i dobra koje nije dobro ni za koga, moral bi nas, skoro potpuno sigurno, naveo da prvom damo prednost nad drugim. Šta znači dobro za nekog? Znači da je korisno, odnosno upotrebljivo. Mnogi smatraju da je ovo osiromašena teorija dobra jer poistovećuje dobro i poželjno, i pitanje svodi na zahtev konzumiranja. Utilitaristi zaključuju da je ispravan postupak onaj postupak koji uvećava korist.

„Bentam je tvrdio da njegov utilitaristički princip - da mi treba da postignemo što veću sreću za što veći broj - jeste na prvi pogled racionalan i da pruža racionalan metod za donošenje moralnih odluka." [1, s.222] Džon Stjuart Mil (1806-1873) u svom delu Utilitarizam zastupa moral zdravog razuma koji smo naučili još kao deca, odnosno, akumuliranu mudrost čovečanstva o poželjnim i nepoželjnim posledicama postupanja. Zbog toga mi možemo i moramo da živimo po njemu, osim u uobičajenim ili novim situacijama kada je prikladno pozivanje na princip korisnosti.

Kritičari utilitarizma (korisnosti) smatraju da postoje stvari - istina, lepota, ljubav, prijateljstvo - koje su dobre bilo da ih ljudi žele ili ne.

Utilitaristi odgovaraju da postoje interesi dobrobiti koji se sastoje od skupa generalizovanih resursa, koje će ljudi nužno morati da imaju pre nego što ostvare neku posebnu sklonost koju bi mogli da imaju. Zdravlje, novac, stan, izdržavanje i tome slično, su očigledno ta vrsta interesa dobrobiti, korisni resursi, bez obzira na ljudske posebne planove i projekte. [1, s.354]

\section{ZAKLJUČAK}

Moral ne mora biti spolja nametnut, već se shvata kao ljudsko vladanje samim sobom ili kao autonomija. Pojednici imaju pravo da određuju sopstvene ciljeve i moral sadrži uslove pod kojim oni mogu da se najbolje ostvare. Slično kao kod Kanta, Džon Rols ističe pojam moralne jednakosti, a društveni ugovor je takva procedura koja otelotvoruje principe nepristrasnog razmatranja - da svaka ličnost uzima u obzir potrebe drugih kao slobodnih jednakih bića.

Pristojno ponašanje je pokrenuto različitim vrstama motiva, koji slede iz uviđanja potreba drugih, kao što su osećanje pravde, prijateljstvo, simpatija, porodično osećanje, velikodušnost, zahvalnost ili lojalnost. Ove osobine su u većini ljudskih društava priznate i poštovane. Džon Lok je tvrdio da su prava neotuđiva i da zbog toga postoje moralne granice za ono što vlast može da čini. Pretnje kaznom su ipak potrebne da se većina privoli na pristojno ponašanje. Hjum je dokazivao da moral mora biti ukorenjen u našim osećanjima, jer nas pokreće na delovanje a sam razum to nikada ne čini.

Hegel je smatrao da moralna ličnost mora da bude oblikovana od strane zajednice u kojoj živi, ali i da preko racionalnog istraživanja, pronađu nova rešenja za društvene probleme, svesno radeći na reformi svoje zajednice i njenih moralnih pogleda.

„Društveni instikti - prvobitni princip ljudske moralne konstitucije - uz pomoć aktivnih intelektualnih sposobnosti i posledica navike prirodno vode zlatnom pravilu po kome sve što hoćete da čine vama ljudi, tako činite i vi njima, a to leži u samom temelju morala." [1, s.21] Teško da bi bilo i kuture bez takvog stava, jer je moralno značenje snažno uslovljeno kulturom.

Džon Meki ističe da su moralni sudovi univerzabilni. $[4$, s.80]

- Pojedinačni slučaj se zamenjuje opštim opisom (sloboda);

- Univerzalne maksime ne zavise od mentalnih ili fizičkih kvaliteta, ne zavise od prihoda ili društvenog statusa (pravičnost);

- posmatraju se stavovi sa sopstvenog gledišta i sa gledišta druge osobe istovremeno i principi prihvatljivi za oba (utilitarizam)

\section{LITERATURA}

[1] Piter Singer (priredio), 2004, Uvod u etiku, Izdavačka knjižarnica Zorana Stojanovića, Sremski Karlovci, Novi Sad.

[2] Miloš N. Đurić, 1997, Istorija helenske etike, Zavod za udžbenike i nastavna sredstva, Beograd.

[3] Aristotel, 2013, Nikomahova etika, Izdavačka knjižarnica Zorana Stojanovića Sremski Karlovci.

[4] Džon Meki, 2004, Etika: opšta teorija o ispravnom i neispravnom, Plato, Beograd.

[5] Imanuel Kant, 1979, Kritika praktičkog uma, BIGZ, Beograd.

\section{Abstract:}

The basis of ethics is the correct behavior of people, from early civilization to the present. The paper reveals which treatment we consider good and right and how ethics affects on the basic rules of life. On the other side ethics helps us to work better and more efficient. ethics,

virtue, natural law, utilitarism.

\section{Key words:}

